\title{
European Societies
}

\section{The working class left behind? The class gap in life satisfaction in Germany and Switzerland over the last decades}

\section{Oliver Lipps \& Daniel Oesch}

To cite this article: Oliver Lipps \& Daniel Oesch (2018): The working class left behind? The class gap in life satisfaction in Germany and Switzerland over the last decades, European Societies, DOI: 10.1080/14616696.2018.1448106

To link to this article: https://doi.org/10.1080/14616696.2018.1448106

Submit your article to this journal $\widetilde{ }$

Q View related articles $₫$

View Crossmark data $₫$ 


\title{
The working class left behind? The class gap in life satisfaction in Germany and Switzerland over the last decades
}

\author{
Oliver Lipps ${ }^{a}$ and Daniel Oesch ${ }^{b}$
}

${ }^{a}$ FORS, Swiss Centre of Expertise in Social Sciences, c/o University of Lausanne, Lausanne, Switzerland; 'bife Course and Inequality Research Centre (LINES), University of Lausanne, Lausanne, Switzerland

\begin{abstract}
The 1990s and 2000s were a gloomy period for Germany's working class, hit by mass unemployment, welfare retrenchment and wage stagnation. We examine whether the growing economic disparity between the top and the bottom of Germany's class structure was accompanied by a widening class gap in life satisfaction. We analyse whether there is a social class gradient in life satisfaction and whether, over the last decades, this class gradient increased in Germany, relative to the comparison case of Switzerland. We use panel data for Germany (1984-2014) and Switzerland (2000-2015) and check the robustness of our results by replicating our analysis with the pooled German and Swiss samples of the European Social Survey (2002-2014). In both countries, respondents in higher classes report substantially higher life satisfaction than those in lower classes. The class gap is twice as large in Germany than in Switzerland. In Germany, the class gap in life satisfaction narrowed between 1984 and 1990, strongly widened between 1990 and 2005 and then decreased again after 2010. In Switzerland, the class gap did not follow a clear time trend, but remained basically constant. In Germany, differences in unemployment risks and household income account for half of the class gap and its evolution over time.
\end{abstract}

ARTICLE HISTORY Received 6 April 2017; Accepted 1 March 2018

KEYWORDS Life satisfaction; social class; unemployment; Germany; Switzerland; income inequality

\section{Introduction}

One of the driving forces behind the Brexit vote and the election of Donald Trump was arguably working-class discontent - the increasingly bleak life chances of blue collar workers (O'Reilly et al. 2017). The American and British working classes are not alone in facing difficult prospects. The two decades between the fall of the Wall and the Great Recession were 
not a good period for Germany's working class either. Mass unemployment, welfare state retrenchment and the decline of trade unions weakened low-educated workers' position in the labour market. As a result, the 1990s and 2000s brought a rise in low-paid work and wage inequality (Bosch 2009). While real wages increased at the top of the earnings distribution, they declined at the bottom (Antonczyk et al. 2010).

The widening gap in life chances between the top and the bottom of Germany's class structure - between the upper-middle and the working class - is well documented (Streeck 2009). The question raised in this paper is whether this growing economic disparity was also accompanied by an increasing gap in workers' life satisfaction. We answer this question by analysing for Germany the extent and evolution of the social class gradient in life satisfaction since the mid-1980s. Our paper thus examines whether, over the last decades, the gap in subjective well-being between the upper-middle and the working class widened in Germany.

A sizable body of research analyses inequality in life satisfaction over time and across countries by measuring the variance of life satisfaction within the entire population (e. g. Alesina et al. 2004; Delhey and Kohler 2011). Enquiries into the social class gradient of life satisfaction are harder to come by. While the gap in life satisfaction between the lowest and the highest income tertiles seems to have widened in the US between 1990 and 2005 (Barnes and Hall 2013), the disparity in psychological well-being appears to be stable between the working and middle classes in Britain since the early 1990s (Richards and Paskov 2016).

With respect to Germany, we know that the working class has lost out in terms of earnings between the mid-1990s and the mid-2000s (Bosch 2009). The open question is as to whether it was also left behind in terms of life satisfaction. Even if there is an increasing gap in life satisfaction between social classes in Germany, this gap may be driven by other causes than the increasing disparity in economic opportunities. Notably, it may be the result of international trends such as globalization (and offshoring) or skill-biased technological change (and automation), which arguably make life more difficult for the lower classes everywhere in Western Europe.

We address this issue by comparing the evolution in life satisfaction in Germany with that in Switzerland, a neighbouring country that was exposed to the same shifts in trade and technology, but where labour market institutions, wage inequality and the proportion of low-paid work remained basically constant over the last two decades (Grabka and Kuhn 2012). 
Our paper makes three contributions. First, it presents novel evidence on the surprisingly large extent of the class gap in life satisfaction in Germany and Switzerland - and uses the best available microdata to show how it evolved over the last decades. Second, it shows that during Germany's long economic stagnation of the 1990s and early 2000s, the social class gradient in life satisfaction widened, while it remained basically constant in the comparison case of Switzerland. The main driver behind this growing class gap was the differential exposure of the upper-middle and the low-skilled working class to the risk of unemployment and low earnings. Finally, our paper addresses the scepticism about the feasibility of reliably measuring life satisfaction by replicating our analysis with a second data set. We present results based on the German Socio-Economic Panel (SOEP) 1984-2014, and the Swiss Household Panel (SHP) 20002014 as well as on the German and Swiss samples of the European Social Survey (ESS) 2002-2014.

We first discuss the literature on inequality in subjective well-being. We then show that Germany's working class was left behind during the country's long economic stagnation of the 1990s and early 2000s, leading to our hypothesis of a widening class gap in life satisfaction in Germany, but not in Switzerland. We then discuss our data, measures and estimation method and present our results for the evolution of the social class gradient in life satisfaction in Germany and Switzerland. The conclusion puts our findings into a larger context.

\section{The link between economic inequality and life satisfaction}

Research on subjective well-being has become a growth industry in recent years, spurred by the increasing availability of surveys that include questions about life satisfaction and happiness. If one focuses on studies covering at least a decade worth of data, the commonly reported finding is that larger income inequality is linked with larger inequality of life satisfaction in a given country and period (Alesina et al. 2004; Oishi et al. 2011; Delhey and Dragolov 2014). Two recent reviews of the literature conclude that higher levels of economic inequality tend to be associated, in Western societies, with lower levels of subjective well-being (Senik 2009: 3, Schneider 2016: 1725).

At the same time, there is a well-established finding that inequality in life satisfaction has been falling in most Western countries since the early 1980s (Veenhoven 2005: 474; Clark et al. 2016). This evolution is puzzling as we observe, over the same period, a U-turn in income 
inequality with widening gaps between top earners and low earners (Alderson and Nielsen 2002; OECD 2011a).

Unlike for the bulk of countries, the evolution in life satisfaction is ambiguous for the United States and Germany. In the US, inequality in life satisfaction decreased from its highest level in the 1970s all the way through the 1990s, but started to rise again in the 2000s (Dutta and Foster 2013). When decomposing changes in the distribution of subjective well-being between 1972 and 2006, Stevenson and Wolfers (2008: 74) find that the black-white gap in life satisfaction has declined and the gender gap disappeared. Yet the inequality in life satisfaction by education - possibly a proxy for the social class gradient - has increased: life satisfaction was rising among college graduates, decreasing among respondents with some college and falling sharply among those with a high school degree or less. This result is consistent with the finding that life satisfaction in the US has grown in the top income tertile between 1990 and 2005, while it declined in the bottom income tertile (Barnes and Hall 2013: 213-14).

In Germany, inequality in life satisfaction seems to have steadily decreased during the 1980s and early 1990s. Starting from the mid1990s, the evolution has either been described as trendless fluctuation (Clark et al. 2016) or, less persuasively, as showing a slight increase in inequality (Becchetti et al. 2013). What seems undisputed is that the 1990s saw a break in the downward trend towards less inequality in subjective well-being.

What are the mechanisms that lead from economic inequality to life satisfaction? A first argument is rooted in sociology and expects income inequality to increase social distance and reduce the feelings of togetherness. Material inequality thus erodes social trust and social capital, thereby making a community less liveable (Veenhoven 1995; Delhey and Dragolov 2014). A second argument draws on social psychology and maintains that growing income inequality exacerbates unfavourable status comparisons and leads to greater status anxiety (Wilkinson and Pickett 2009). A third argument stems from political science and expects rising income inequality to result in heightened conflicts over material resources and lower overall life satisfaction (Haller and Hadler 2006). Empirical evidence suggests that perceptions of social trust and status anxiety - but less so of conflicts - mediate the inequality-well-being link in Europe (Delhey and Dragolov 2014).

While this research strand examines how income inequality observed at the level of a region or country affects the subjective well-being of individuals, our objective is somewhat different. We aim at uncovering the extent - and the evolution - of the disparity in life satisfaction across social 
classes. By analysing the social class gradient in well-being and its evolution over time, our focus is on economic mechanisms and on how earnings and unemployment risks affect the life satisfaction of people in different class positions.

\section{The German working-class left behind}

Why would we expect a rising gap in life satisfaction across different social classes in Germany since the 1990s? Our argument is that over the last two decades, the economic destiny of the working and the upper-middle class has diverged strongly, notably in terms of unemployment risks, working conditions and earnings.

During the post-reunification recession, unemployment rose rapidly and remained at over $8 \%$ for 15 years in a row, from 1993 to 2007. In Germany, unemployment afflicted low-educated workers - mostly set in the low-skilled working class - much more than high educated workers. Over the 1990s, the unemployment rate of workers with no more than 10 years of formal education was, on average, 2.6 times higher than that of workers with tertiary education. Over the 2000s, this ratio increased to 3.8 (OECD, Education at a Glance, various years).

During this long crisis, there was a weakening of the collective institutions that impose public obligations on employers and thus primarily benefit workers with little bargaining power: older workers, those in temporary contracts and the working class more generally (Carr and Chung 2014). Trade unions and work councils came under pressure during the long economic stagnation of the 1990s when unemployment rose, while union membership and coverage of collective agreements dropped. Between 2003 and 2005, the Hartz laws redesigned the German welfare state by making unemployment benefits less generous.

The triple influence of persistently high unemployment, weaker collective pay-setting institutions and reduced unemployment benefits put Germany's working class under increased market pressure and decreased the wage floor (Oesch 2013). The result was, after the 1990s, an unprecedented rise in low-wage (and often atypical) work (Eichhorst and Marx 2011) and income inequality (Antonczyk et al. 2010). In the early 2000s, income inequality in Germany increased more than twice as much as in the average of the OECD (OECD 2011b).

What do these shifts in the labour market mean for the social class gradient in life satisfaction? As Germany's institutional safeguards have become less effective at sheltering low-skilled workers from low earnings and 
unemployment, we would expect an increasing class gradient. More precisely, over the last two decades, the gap in life satisfaction between the uppermiddle and low-skilled working class should have widened in Germany.

\section{Contrasting the German experience with Switzerland}

Our hypothesis of a widening disparity in life satisfaction could be countered by the argument that this increasing gap may well be due to other factors than the rise of unemployment and earnings inequality and the dismantling of labour market institutions. Low-educated workers may have come under pressure everywhere in the OECD as a consequence of either international trade and offshoring or skill-biased technological change and automation. Life may, thus, have become more difficult for low-educated workers across Europe, the situation in Germany being by no means particular.

An ideal case to contrast the German experience - and the effect of unemployment and income inequality - is neighbouring Switzerland. Switzerland has a majority of German-speakers and shares several institutional features with Germany, from vocational education to industrybased collective bargaining. However, contrary to Germany, Switzerland's unemployment rate remained low, its wage-setting institutions were not dismantled and unemployment benefits are comparatively generous with a replacement rate of $70-80 \%$ over $18-24$ months. The generosity of benefits is not irrelevant: the adverse effect of unemployment on life satisfaction in Europe seems to almost double if unemployment benefits are meagre (Wulfgramm 2014, see also Carr and Chung 2014). Most importantly, in Switzerland, the trend in wage inequality was basically flat and thus stands in stark contrast to the steep increase in Germany (OECD 2011b; Grabka and Kuhn 2012; Kuhn and Suter 2015). By comparing the evolution of life satisfaction in Germany with that in Switzerland, we obtain a contrast case where unemployment and income inequality remained basically constant over the last two decades.

\section{Data, measures and estimation method}

\section{Datasets}

Our empirical analysis uses the German SOEP, waves 1984-2014 (SOEP v31, Wagner et al. 2007) and the SHP, waves 2000-2015 (Voorpostel et al. 2014). We increase the robustness of our results by following the practice 
of 'identical analysis of parallel data' (Firebaugh 2008) and thus estimate the same models on two additional data sets, namely the German and Swiss samples of the ESS 2002-2014. The replication across different data sets allows us to gauge the uncertainty in the results that may be due to errors commonly found in surveys such as errors linked to coverage, sampling, non-response and measurement (Groves 2004).

All our data sets are nationally representative and collect information on labour market status and life satisfaction. Prior to 1990, the German SOEP only included West German respondents. In order to examine the same population over time, we limit our analytical sample to West Germany. In addition, we only include respondents aged between 30 and 64 years. Thereby, we exclude people who are still in education and who, while in their early work career, have not yet obtained a stable class position. Overall, this leaves us with samples of 35,082 individuals (250,261 observations) (SOEP) and 6847 individuals (ESS) for West Germany and 11,977 individuals (64,623 observations) (SHP) and 6181 individuals (ESS) for Switzerland.

\section{Variables and measures}

Our dependent variable is self-reported life satisfaction and based on the question: 'How satisfied are you with your life, all things considered?', with answers ranging from 0 (completely dissatisfied) to 10 (completely satisfied). Although this 11-point scale is, strictly speaking, an ordinal variable, we follow the established practice in the well-being literature and treat it as a cardinal variable (Ferrer-i-Carbonell and Frijters 2004). This allows us to compute the mean value of life satisfaction.

Our key independent variable is social class where we use an aggregated version of the schema proposed by Erikson and Goldthorpe (1992) and distinguish four hierarchically ordered classes: (i) the upper and uppermiddle class containing large employers, managers and professionals; (ii) the lower-middle class including small employers, technicians and associate professionals; (iii) the skilled working class including clerks, craftsmen, skilled service and sales workers; (iv) the low-skilled working class containing assemblers, machine operators, farmhands, low-skilled service and sales workers, and other elementary occupations. Respondents are allocated to one of these four classes based on their current occupation or, if missing, their past occupation. If both variables are missing, we use the partner's occupation. We, thus, also attribute a class location to the unemployed and economically inactive. The idea is that unemployed 
lawyers (or an economically inactive person married to a lawyer) face different life chances than an unemployed assembler (or an economically inactive person married to an assembler).

The key information to build our class measure comes from occupations (measured with ISCO 1988 4-digit). Additionally, we use information on self-employment and the number of employees to allocate employers with more than nine employees to the upper-middle class, regardless of their occupation. In a similar vein, small employers (one to nine employees) whose occupation is neither manager nor professional are attributed to the lower-middle class. ${ }^{1}$

We examine whether class differences in life satisfaction are due to differences in unemployment and income inequality by using variables at both the individual and contextual level. We measure unemployment at the individual level by distinguishing three different employment statuses (in paid work, unemployed, out of the labour force). At the contextual level, we use the annual unemployment rate of a given Bundesland (Germany) or greater region (Switzerland). ${ }^{2}$ For earnings, we use the logarithm of the equivalent household (post-government) total income, taking into account all sources of income. At the contextual level, we measure income inequality as the ratio p80/p20 of equivalent household incomes in a given Bundesland or greater region in a given year.

In addition, we introduce control variables for sex, age group, Bundesland/greater region, nationality (national vs. non-national) and living together with a partner. Of particular interest are period effects; we introduce calendar year both as a linear term and, to check for a non-linear evolution over time, as yearly dummies. Table A1 in the appendix shows the descriptive statistics of our variables.

\section{Method and model}

We first examine the evolution of life satisfaction across social classes by calculating the yearly means, using weighted scatterplot smoothing (LOWESS). ${ }^{3}$ We then analyse a multivariate between-estimator (BE)

\footnotetext{
${ }^{1}$ For more detail on the concept and measurement of the class variable, see Oesch (2006). The script used for the construction of this class schema can be downloaded in Stata or SPSS from one of the authors' webpage: http://people.unil.ch/danieloesch/.

${ }^{2}$ Although the relevant political unity at Switzerland's subnational level is the canton, our yearly samples are too small to provide a sufficient number of observations for each of the 26 cantons that vary widely in size. Instead, we use the more aggregate level of Switzerland's seven great regions.

${ }^{3}$ In order to reduce the influence of short-term fluctuations and to better grasp the time trend, we use weighted scatterplot smoothing (LOWESS). This means that we compute the mean life satisfaction in a given year by borrowing additional information from adjacent years, where nearest neighbouring
} 
model, which solely uses the cross-sectional (between) variance in life satisfaction, and not the time (within) variance. The rationale behind using between-variance only is that classes are largely composed of the same people over time, as entry into a class is contingent on time-constant factors such as social origin and, above all, education. A medical doctor is likely to belong to the upper-middle class over the entire career and a farmhand without post-mandatory education is unlikely to leave the low-skilled working class.

Of course, there is some initial job hopping and (short-range) occupational mobility at the beginning of careers. For this reason, we exclude respondents younger than 30 from our analytical sample. However, most people arrive at their stable class position over the course of their thirties (Erikson and Goldthorpe 1992: 72; Mayer 2000: 274). A transition matrix for the German SOEP tells us that only a small share of all workers is mobile across classes: on average, $12 \%$ in the low-skilled working class and $8 \%$ in the upper-middle class change class from one year to the next over our period of observation. Moreover, there is ample evidence that occupational changes are overestimated in panel surveys due to measurement errors (Perales 2014).

By using the BE, we do not enquire about how individual mobility between classes affects the life satisfaction of the small minority of mobile people. Rather, we focus on how life satisfaction varies between different classes in a given year and over a given period. We, therefore, treat our longitudinal panel data (SOEP and SHP) the same way as our repeated cross-sectional data (ESS) where the $\mathrm{BE}$ corresponds to a simple OLS regression. Of course, this means that our analysis of life satisfaction in two countries has little causal traction. We are much better prepared to describe how life satisfaction varies between different classes over time than to explain why it varies.

The equation of our linear regression model is given as:

$$
\begin{aligned}
y_{i t}= & \beta_{1}+\beta_{2} \text { class }_{i t}+\beta_{3} \text { year }_{i t}+\beta_{4} \text { class }_{i t} * \text { year }_{i t}+\beta_{5} \text { controls }_{i t} \\
& +\epsilon_{i t} .
\end{aligned}
$$

The dependent variable $y_{\mathrm{i}}$ is the 11-point measure of the life satisfaction of individual $i$ at time $t$. Controls $s_{i t}$ include our measures of unemployment and household income (as well as sex, age, region, nationality and 
partnership) and $\varepsilon_{i t}$ is the idiosyncratic error term. Our main predictor is social class, class $i t$, while year ${ }_{i t}$, captures the period effect (entered as a linear term or as a set of yearly dummies), allowing us to estimate the interaction between class and period, class ${ }_{i t} *$ year $_{i t}$. If there is a different evolution in life satisfaction between classes over periods, this effect will be picked up by the interaction term. We correct for auto-correlation in our panel data by using panel-corrected clustered standard errors.

\section{The class gap in life satisfaction over time}

Before we estimate a multivariate model, we provide descriptive evidence for the class difference in life satisfaction in Germany and Switzerland. Figures 1 and 2 show the evolution of life satisfaction in each class (lefthand panel) and plot the difference in life satisfaction between the highest and lowest class (right-hand panel). We observe the same class pattern for both countries, with higher classes consistently reporting higher life satisfaction than lower classes.

Life satisfaction in West Germany fell during the 1980s for all classes (see Figure 1). In the early 1990s, the fall came to a standstill for the upper-middle class, but continued for the other classes. Life satisfaction decreased for the low-skilled working class until 2007/2008, and then began to rise again. Accordingly, the gap in life satisfaction between the top and bottom was the smallest during the reunification boom 1990 to 1991, and the largest in 2008-2010, before the recovery of the German labour market finally began in earnest. At its maximum, the class disparity
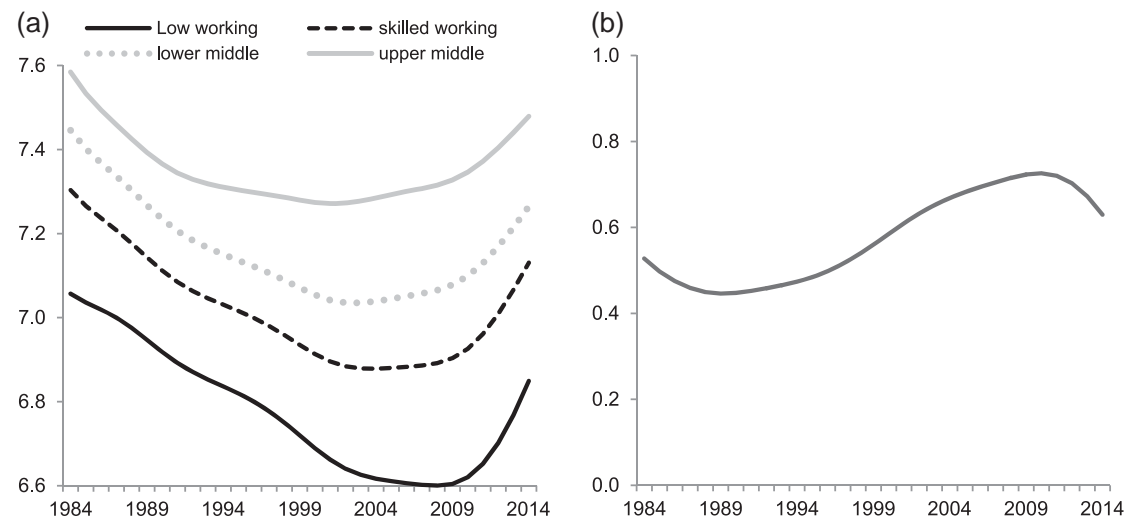

Figure 1. The class gradient in life satisfaction (on a scale from 0 to 10) in West Germany (SOEP 1984-2014). (a) Life satisfaction by social class in West Germany. (b) Difference in life satisfaction between the upper-middle and low-skilled working class. 

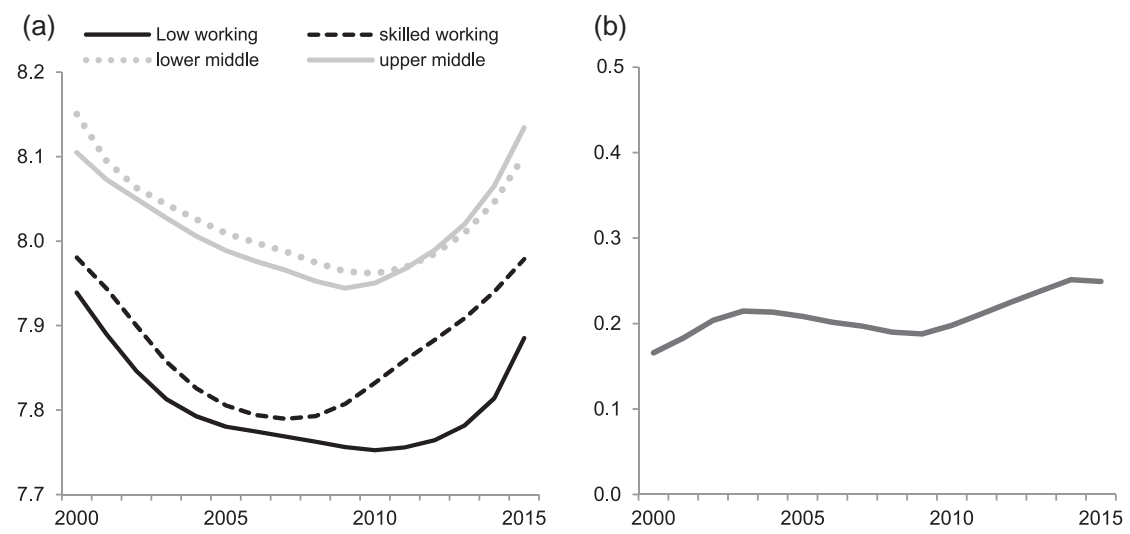

Figure 2. The class gradient in life satisfaction (on a scale from 0 to 10) in Switzerland (SHP 2000-2015). (a) Life satisfaction by social class in Switzerland. (b) Difference in life satisfaction between the upper-middle and low-skilled working class.

in life satisfaction was 0.73 points on the 11-point life satisfaction scale and hence comparable to the gap in life satisfaction between the more satisfied people who have a partner and the less satisfied people who do not have a partner (see Table 1 for the estimates).

Workers seem more satisfied with their lives in Switzerland than in Germany. Mean levels in Switzerland exceed those in Germany by over half a point (see Figure 2). Not only the levels of life satisfaction are higher, but also the class gap in life satisfaction is smaller in Switzerland. The disparity between the highest and lowest class is less than half as large as in Germany, fluctuating between a minimum of 0.17 and a maximum of 0.25 between 2000 and 2015 . There is no clear trend in the disparity of life satisfaction over time in Switzerland. While we observe a downward trend in life satisfaction for all classes up to 2009, the recovery thereafter came later and was somewhat weaker for the low-skilled working class than the other classes.

We check our results by replicating the same analysis with another data set covering a shorter time period, the ESS. For both countries, we find again the same hierarchical rank-ordering of life satisfaction by class: the more privileged the class position, the higher the satisfaction with life (see Figures A1 and A2 in the appendix). Class differences are somewhat larger in the ESS. Over the period 2002-2014, the gap in life satisfaction between the lowest and the highest class amounts to an average of 0.4 for Switzerland and 0.9 points for Germany (as compared to 0.2 and 0.7 when measured with the SHP and SOEP, respectively, over the same period 2002-2014). 
Table 1. Linear regression coefficients for life satisfaction (from 0 to 10) in West Germany.

\begin{tabular}{|c|c|c|c|c|c|c|}
\hline & \multicolumn{3}{|c|}{ SOEP 1984-2014 } & \multicolumn{3}{|c|}{ ESS 2002-2014 } \\
\hline & $\begin{array}{c}\text { M1 } \\
\text { baseline }\end{array}$ & $\begin{array}{c}\mathrm{M} 2 \\
\text { unemployment }\end{array}$ & $\frac{\mathrm{M} 3}{\text { unemployment + income }}$ & $\begin{array}{c}\text { M1 } \\
\text { baseline }\end{array}$ & $\begin{array}{c}\mathrm{M} 2 \\
\text { unemployment }\end{array}$ & $\begin{array}{c}\text { M3 } \\
\text { unemployment + income }\end{array}$ \\
\hline \multicolumn{7}{|l|}{ Class (ref: upper-middle) } \\
\hline Low-skilled working & $-0.47^{* * *}$ & $-0.46^{* * *}$ & $-0.23^{* * *}$ & $-0.97^{* * *}$ & $-0.90^{* * *}$ & $-0.67^{* * *}$ \\
\hline Skilled working cl. & $-0.28^{* * *}$ & $-0.23^{* * *}$ & -0.06 & $-0.60^{* * *}$ & $-0.55^{* * *}$ & $-0.39^{* *}$ \\
\hline Lower-middle class & $-0.19^{* * *}$ & $-0.19^{* * *}$ & $-0.12^{*}$ & $-0.36^{* * *}$ & $-0.36^{* * *}$ & $-0.26^{* *}$ \\
\hline Year & -0.00 & -0.00 & $-0.02^{* * *}$ & $0.02^{* *}$ & -0.00 & -0.01 \\
\hline \multicolumn{7}{|l|}{ Interactions } \\
\hline Low-skilled $\times$ year & $-0.01^{* * *}$ & -0.00 & 0.00 & 0.02 & 0.03 & $0.05^{*}$ \\
\hline Skilled $\times$ year & $-0.01^{* *}$ & $-0.00^{*}$ & -0.00 & 0.02 & 0.02 & 0.03 \\
\hline Lower-middle $\times$ year & -0.00 & 0.000 & 0.00 & 0.03 & 0.03 & $0.04^{*}$ \\
\hline Has a partner & $0.55^{* * *}$ & $0.48^{* * *}$ & $0.45^{* * *}$ & $1.19^{* * *}$ & $1.13^{* * *}$ & $0.83^{* * *}$ \\
\hline \multicolumn{7}{|c|}{ Labour market status (ref: employed) } \\
\hline Out of labour force & & $-0.29^{* * *}$ & $-0.16^{* * *}$ & & $-0.24^{* * *}$ & $-0.16^{*}$ \\
\hline Unemployed & & $-1.42^{* * *}$ & $-1.10^{* * *}$ & & $-1.03^{* * *}$ & $-0.76^{* * *}$ \\
\hline Unemployment rate & & $-0.03^{* * *}$ & $-0.03^{* * *}$ & & $-0.07^{* * *}$ & $-0.08^{* * *}$ \\
\hline Household income & & & $0.56^{* * *}$ & & & $0.14^{* * *}$ \\
\hline Regional inequality & & & 0.06 & & & $0.07^{*}$ \\
\hline$R^{2}$ & 0.084 & 0.116 & 0.136 & 0.107 & 0.127 & 0.145 \\
\hline$N$ & 250,261 & 250,261 & 250,261 & 6847 & 6847 & 6,847 \\
\hline
\end{tabular}

Note: All models additionally control for sex, age group, nationality, region, and, in the SOEP, for the type of sample.

${ }^{* * *} p<.01,{ }^{* *} p<.05,{ }^{*} p<.1$. 
For the time trend in life satisfaction, the ESS paints a slightly different picture. For Germany, we observe a slight increase - and stability thereafter - in the class gradient between 2002 and 2006 (when life satisfaction declines for all classes). Thereafter, the recovery in life satisfaction is stronger for the working classes than the upper-middle class, leading to a (slight) narrowing of the class gap. In Switzerland, the class gap in life satisfaction widens between 2002 and 2006 and, after a period of stability, increases again between 2012 and 2014.

\section{A multivariate analysis of the class gap in life satisfaction}

We further examine the link between class and life satisfaction with a multivariate model. The coefficients of interest are shown for Germany in Table 1 (for the SOEP and ESS) and for Switzerland in Table 2 (for the SHP and ESS). After controlling for sex, age, nationality, partnership, region and year, we still find a large main effect for class in Germany (see model M1). In 1984, the members of the low-skilled working class were less satisfied by 0.47 points (SOEP) than their counterparts of the upper-middle class. The interaction between class and years suggests that with every 10 years that passed, the class gap increased by another 0.10 points. Compared with the upper-middle class, the members of the low-skilled working class have become increasingly dissatisfied with their lives over the last three decades. In the ESS, we obtain a class gap of 0.97 for 2002 - without any clear class differences over the following decade.

If we further control in model M2 for being unemployed or economically inactive as well as for the regional unemployment rate, the main effect decreases only slightly, but the negative time trend in the SOEP for the low-skilled working class disappears. As is visible if we plot these results graphically, this means that the widening class gap between 1990 and 2005 is partly due to the differential risk of social classes to experience unemployment. If we further add two income measures at the individual and regional level, the class effects are (almost) halved (see model M3). The difference in life satisfaction between the upper-middle and the lowskilled working class drops from 0.46 to 0.23 in 1984 (SOEP) and from 0.97 to 0.67 in 2002 (ESS). This underlines that class position and earnings are closely correlated - and that lower classes are less satisfied with their lives because they find it harder to make ends meet.

In Switzerland, our two data sets cover almost the same period, and the class coefficients for the two samples are very similar. Both the SHP and ESS indicate that net of sex, age, nationality, partnership and region, the 
Table 2. linear regression coefficients for life satisfaction (from 0 to 10) in Switzerland.

\begin{tabular}{|c|c|c|c|c|c|c|}
\hline & \multicolumn{3}{|c|}{ SHP 2000-2015 } & \multicolumn{3}{|c|}{ ESS 2002-2014 } \\
\hline & $\begin{array}{c}\text { M1 } \\
\text { baseline }\end{array}$ & $\begin{array}{c}\mathrm{M} 2 \\
\text { unemployment }\end{array}$ & $\begin{array}{c}\mathrm{M} 3 \\
\text { unemployment }+ \text { income }\end{array}$ & $\begin{array}{c}\text { M1 } \\
\text { baseline }\end{array}$ & $\begin{array}{c}\mathrm{M} 2 \\
\text { unemployment }\end{array}$ & $\begin{array}{c}\mathrm{M} 3 \\
\text { unemployment + income }\end{array}$ \\
\hline \multicolumn{7}{|l|}{ Class (ref: upper-middle) } \\
\hline Low-skilled working & $-0.34^{* * *}$ & $-0.32^{* * *}$ & $-0.19^{* *}$ & -0.34 & -0.33 & -0.18 \\
\hline Skilled working cl. & $-0.27^{* * *}$ & $-0.25^{* * *}$ & $-0.15^{* *}$ & -0.11 & -0.10 & 0.00 \\
\hline Lower-middle class & -0.02 & -0.02 & 0.04 & 0.08 & 0.07 & 0.12 \\
\hline Year & $0.02^{* * *}$ & $0.02^{* * *}$ & $0.02^{* * *}$ & 0.02 & 0.01 & $0.04^{* *}$ \\
\hline \multicolumn{7}{|l|}{ Interactions } \\
\hline Low-skilled $\times$ Year & 0.00 & 0.00 & 0.00 & -0.02 & -0.02 & -0.01 \\
\hline Skilled $\times$ Year & 0.01 & 0.01 & 0.01 & -0.02 & -0.02 & -0.01 \\
\hline Lower-middle $\times$ Year & -0.00 & -0.00 & -0.00 & $-0.04^{* *}$ & $-0.04^{* *}$ & $-0.03^{*}$ \\
\hline Has a partner & $0.74^{* * *}$ & $0.73^{* * *}$ & $0.71^{* * *}$ & $0.63^{* * *}$ & $0.61^{* * *}$ & $0.46^{* * *}$ \\
\hline \multicolumn{7}{|c|}{ Labour market status (ref: employed) } \\
\hline Out of labour force & & $-0.25^{* * *}$ & $-0.16^{* * *}$ & & $-0.12^{* *}$ & $-0.09^{*}$ \\
\hline Unemployed & & $-1.27^{* * *}$ & $-1.17^{* * *}$ & & $-1.12^{* * *}$ & $-1.01^{* * *}$ \\
\hline Unemployment rate & & -0.01 & -0.02 & & $0.06^{* *}$ & 0.02 \\
\hline Household income & & & $0.31^{* * *}$ & & & $0.09^{* * *}$ \\
\hline Regional inequality & & & $1.13^{* * *}$ & & & 0.07 \\
\hline$R^{2}$ & 0.083 & 0.091 & 0.104 & 0.059 & 0.073 & 0.087 \\
\hline N & 64,623 & 64,623 & 64,623 & 6181 & 6181 & 6181 \\
\hline
\end{tabular}

Note: All models additionally control for sex, age group, nationality, and region.

${ }^{* * *} \mathrm{p}<.01,{ }^{* *} \mathrm{p}<.05,{ }^{*} \mathrm{p}<.1$. 
life satisfaction of the low-skilled working class trails that of the uppermiddle class by 0.34 points. While in Germany the class gap in life satisfaction is almost as large as the gap in life satisfaction between partnered and non-partnered individuals, the class gap in Switzerland is only half as large as that observed for partnership. In terms of time trend, the SHP does not show any class-specific evolution. The interaction terms are not statistically significant in the ESS either, but the coefficients suggest that in comparison to the upper-middle class all other classes have become somewhat less satisfied with their lives since the early 2000, notably the lower-middle class.

Household income and income inequality reduce the class coefficient in Switzerland by about a third as in Germany (model M3). In contrast, unemployment has no bearing on the class gap - a finding probably due to the unusually low number of unemployed respondents in our two Swiss data sets.

Our multivariate model assumes that the trend in life satisfaction is linear over time. This assumption is not warranted if the class gap widens during periods of recessions (Germany in the 1990s) and declines during periods of economic recovery (Germany after 2010). Consequently, in a last set of analyses, we enter time into our model as yearly dummy variables. Instead of showing 30 coefficients for years and 90 coefficients for class-year interactions, we plot in Figures 3 and 4 the predicted differences in life satisfaction over time for each class relative to the baseline of the upper-middle class. Apart from the non-linear terms for years, these results are based on the same three models M1-M3 shown in Tables 1 and 2.

Between 1984 and 2014, the class gap in life satisfaction followed four different trends in Germany. The class gap first decreased during the economic boom from 1984 to 1990. It then strongly increased over the long period of economic stagnation between 1990 and 2005. During the years right before and after the Great Recession (which was not a great recession in Germany), the class gap stabilized and, in the last period, began to decrease after 2010 when unemployment dropped and real earnings finally began to rise.

Clearly, the differential evolution in the economic situation of different classes goes a long way to explain the variation in the life satisfaction gap over time. If we control for unemployment in model M2, the class gradient in life satisfaction decreases strongly and gives rise to a curvilinear evolution with a widening gap during the long recession and a decreasing gap after 2008, thus mirroring the cycles of the German economy. If we further account for household earnings and regional income inequality, 

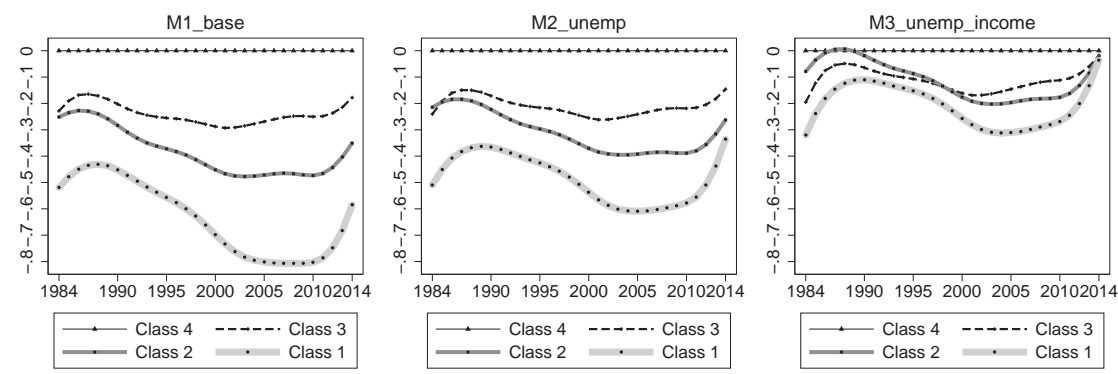

Figure 3. Net class differences in life satisfaction relative to the upper-middle class (on a scale from 0 to 10), Germany 1984-2014. Data: SOEP 1984-2014.

Notes: The figures plot the regression coefficients for each class relative to the horizontal line of class 4 (upper-middle class) net of other control variables. Class 1 refers to 'low-skilled working class', class 2 to 'skilled working class' and class 3 to 'lower-middle class'. Model 1 refers to the baseline model with controls for sex, age, partnership, region and nationality. Model 2 additionally controls for individual and regional unemployment, and model 3 for household income and regional income inequality.
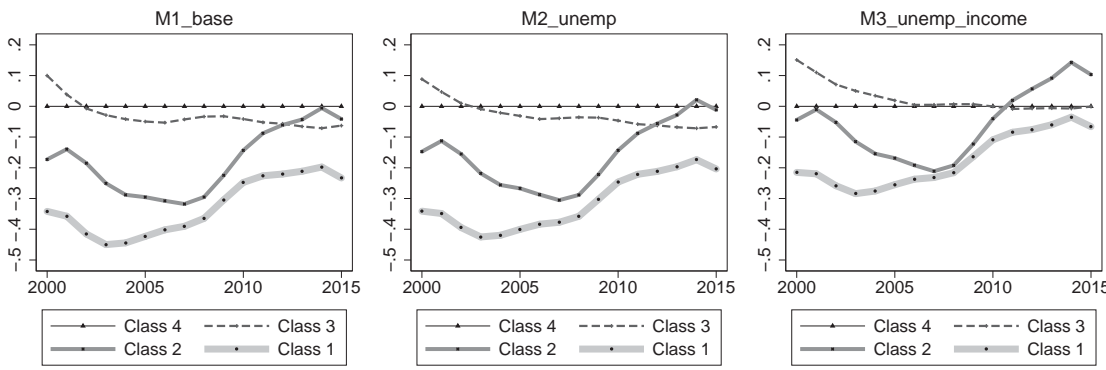

Figure 4. Net class differences in life satisfaction relative to the upper-middle class (on a scale from 0 to 10), Switzerland 2000-2015. Data: SHP 2000-2015. For the legend and model description, see notes in Figure 3.

the disparity between classes in a given year and over time becomes small and amounts to no more than $0.1-0.3$ points.

For Switzerland, the SHP suggests that the class gap in life satisfaction slightly increased at the beginning of the 2000s, but then gradually narrowed up to 2014 (see Figure 4). This finding is not supported by the ESS which suggests that the class gradient first widened in the early 2000s and then further diverged after 2012 (Figure A4 in the appendix).

\section{Conclusion}

Our paper started out with the argument that the last two decades were a gloomy period for Germany's working class. The period between the short reunification boom in 1990 and the mid-2000s when Germany's labour market finally began to recover were marked by mass unemployment, a 
spread of atypical jobs, welfare retrenchment and increasing income inequality. When jobs are harder to come by and economic security decreases, workers with little individual bargaining power - the lowskilled working class - are likely to suffer most (Chung and Mau 2014).

In light of these developments, we had raised the question whether the growing economic inequality in Germany had also led to a widening class gap in life satisfaction. Our analysis of the German SOEP suggests that this was the case during the long economic crisis of the 1990s and early 2000s. While the difference in life satisfaction between the low-skilled working class and the upper-middle class had declined during the boom period of the late 1980s, it constantly increased between 1990 and 2005. Thereafter, it seems to have stabilized and possibly even began to decrease after 2010 when the German labour market had finally recovered and unemployment rates were plummeting.

This downturn in the life satisfaction of the working class may have been driven by external factors that are not particular to Germany. Notably, skill-biased technological change and globalization may make life more difficult for low-skilled workers across the Western world. For this reason, we contrasted the German experience with the comparison case of Switzerland, a neighbouring German-speaking country where labour market institutions, unemployment rates and income inequality remained basically constant over the last two decades (Oesch 2013; Kuhn and Suter 2015).

Our panel data for Switzerland do not show any clear time trend for the period between 2000 and 2015. There was no increasing gap in the early 2000s and no decreasing gap thereafter as in Germany. The yearly changes in the mean life satisfaction of different classes are small and not statistically significant, suggesting that Switzerland's class gradient followed a pattern of trendless fluctuations over time. This finding is consistent with the hypothesis that Germany's widening class gap is not simply part and parcel of a larger cross-national trend with working classes getting less satisfied with their lives everywhere, regardless of the evolution in income inequality and unemployment.

We would rather interpret our results as evidence that the life satisfaction of different classes tends to further diverge during economic crises. As unemployment rises and work income stagnates, the lower classes are disproportionately affected in their subjective well-being. In comparison to their counterparts in the upper-middle class, they are less sheltered from economic downturns and suffer more from the deregulation of institutional safeguards in the labour market. Accordingly, when the economy 
picks up speed again and the labour market recovers - as during the recent economic boom in Germany that set in after the mid-2000s - the lowskilled working class succeeds in reducing the disparity in life satisfaction relative to the upper classes.

We tested the robustness of our findings by replicating our analysis on another data set, the national samples of the ESS 2002-2014. While these additional results confirm the extent of the class gap in life satisfaction in Germany and Switzerland, they are less conclusive about its evolution. For Germany, we still observe a (slight) upward trend in the class gradient until 2004, followed by stability and a decrease between 2006 and 2010 . Yet the ESS diverges from the panel data by showing that the life satisfaction of the low-skilled working class no longer rises after 2012 in Germany or Switzerland - unlike the tendency observed for the upper-middle class. However, since the ESS only provides us with data points for every two years and is based on much smaller national samples, it leads to less precise estimates of the time trend than the two long-running panel data sets that survey respondents every year. We, therefore, have more confidence in the results produced by the panel studies than the ESS.

Nonetheless, the parallel analysis of two data sets leads us to be cautionary in the interpretation of the time trend. The future analysis of additional years will provide a better idea of how Germany's social class gradient in life satisfaction evolved over the current decade. Our study does not provide conclusive evidence as to whether the recent recovery in low-skilled workers' life satisfaction came to a standstill or continued beyond 2012.

While the temporal evolution of the class gap is difficult to pin down, there is little doubt about its extent. In both countries, respondents in higher classes are, on average, more satisfied with their lives than respondents in lower classes. This result holds regardless whether we use the panels or the ESS - and the class gap in life satisfaction is substantially larger in Germany than in Switzerland according to both datasets. Its extent is far from being trivial. In Germany, the difference in subjective well-being between the upper-middle class and the low-skilled working class is almost as large as the gap in life satisfaction between partnered and non-partnered individuals. Yet while public policy has little leverage on the partnership gap in life satisfaction, it is certainly able to reduce the class gradient. Policies that decrease unemployment, increase job security, limit income inequality and stimulate earnings growth all seem viable initiatives to reduce the disparity in subjective well-being between different social classes. 


\section{Disclosure statement}

No potential conflict of interest was reported by the authors.

\section{Notes on contributors}

Oliver Lipps is head of the methodological research programme at the Swiss Centre of Expertise in Social Sciences, FORS, Lausanne, and member of the Swiss Household Panel team. In addition, he is lecturer in survey methodology and survey research at the Institute of Sociology at the University of Bern. He has published widely on issues of survey data quality and substantive issues such as subjective well-being.

Daniel Oesch is Professor at the Life Course and Inequality Research Centre (LINES) at the University of Lausanne. His research focuses on social stratification and inequality, unemployment and labour market policy. He has published widely in the field of economic sociology and is the author of two books: Occupational Change in Europe (Oxford University Press, 2013) and Redrawing the Class Map (Palgrave MacMillan, 2006).

\section{References}

Alderson, A. and Nielsen, F. (2002) 'Globalization and the great U-turn: income inequality trends in 16 OECD Countries', American Journal of Sociology 107(5): 1244-99.

Alesina, A., Di Tella, R. and MacCulloch, R. (2004) 'Inequality and happiness: are Europeans and Americans different?' Journal of Public Economics 88: 2009-42.

Antonczyk, D., Fitzenberger, B. and Sommerfeld, K. (2010) 'Rising wage inequality, the decline of collective bargaining, and the gender wage gap', Labour Economics 17: 835-47.

Barnes, L. and Hall, P. A. (2013) 'Neo-liberalism and social resilience in the developed democracies', in P. A. Hall and M. Lamont (eds), Social Resilience in the Neoliberal Era, Cambridge: Cambridge University Press, pp. 209-38.

Becchetti, L. Massari, R. and Naticchioni, P. (2013). 'The drivers of happiness inequality: suggestions for promoting social cohesion', Oxford Economic Papers 66(2): 419-42.

Bosch, G. (2009) 'Low-wage work in five European countries and the United States', International Labour Review 148(4): 337-56.

Carr, E. and Chung, H. (2014). 'Employment insecurity and life satisfaction: the moderating influence of labour market policies across Europe', Journal of European Social Policy 24(4): 383-99.

Chung, H. and Mau, S. (2014) 'Subjective insecurity and the role of institutions', Journal of European Social Policy 24(4): 303-18.

Clark, A., Flèche, S. and Senik, C. (2016). 'Economic growth evens-out happiness: evidence from Six Surveys', Review of Income and Wealth 62(3): 405-19. 
Delhey, J. and Dragolov, G. (2014) 'Why inequality makes Europeans less happy: the role of distrust, status anxiety, and perceived conflict', European Sociological Review 30(2): 151-65.

Delhey, J. and Kohler, U. (2011) 'Is happiness inequality immune to income inequality? New evidence through instrument-effect-corrected standard deviations', Social Science Research 40 (2011): 742-56.

Dutta, I. and Foster, J. (2013) 'Inequality of happiness in the U.S.: 1972-2010', Review of Income and Wealth 59 (3): 393-415.

Eichhorst, W. and Marx, P. (2011). 'Reforming German labour market institutions: a dual path to flexibility', Journal of European Social Policy 21(1): 73-87.

Erikson, R. and Goldthorpe, J. (1992) The Constant Flux, Oxford: Oxford University Press.

Ferrer-i-Carbonell, A. and Frijters, P. (2004). 'How important is methodology for the estimates of the determinants of happiness?' Economic Journal 114: 641-59.

Firebaugh, G. (2008) Seven Rules for Social Research, Princeton: Princeton University Press.

Grabka, M. and Kuhn, U. (2012) The Evolution of Income Inequality in Germany and Switzerland Since the Turn of the Millennium. Berlin: DIW Berlin. SOEPpapers on Multidisciplinary Panel Data Research464.

Groves, R. M. (2004) Survey Errors and Survey Costs, Hoboken, NJ: Wiley.

Haller, M. and Hadler, M. (2006) 'How social relations and structures can produce happiness and unhappiness: an international comparative analysis', Social Indicators Research 75(2): 169-216.

Kuhn, U. and Suter, C. (2015) 'Die Entwicklung der Einkommensungleichheit in der Schweiz', Social Change in Switzerland 2: 1-14.

Mayer, K. U. (2000) 'Promises fulfilled? A review of 20 years of life course research', European Journal of Sociology 41(2): 259-82.

OECD (2011a) Growing Income Inequality in OECD Countries: What Drives It and How Can Policy Tackle It? Paris: OECD.

OECD (2011b) Divided We Stand: Why Inequality Keeps Rising, Paris: OECD.

Oesch, D. (2006) Redrawing the Class Map. Stratification and Institutions in Britain, Germany, Sweden and Switzerland, Basingstoke: Palgrave Macmillan.

Oesch, D. (2013) Occupational Change in Europe. How Technology and Education Transform the Job Structure, Oxford: Oxford University Press.

Oishi, S., Kesebir, S. and Diener, E. (2011) 'Income inequality and happiness', Psychological Science 22(9): 1095-100.

O’Reilly, J. Froud, J., Johal, S., Williams, K., Warhurst, C., Morgan, G., Grey, C., Wood, G., Wright, M., Boyer, R., Frerichs, S., Sankari, S., Rona-Tas, A. and Le Galès, P. (2017) 'Brexit: understanding the socio-economic origins and consequences', Socio-Economic Review 14 (4): 807-54.

Perales, F. (2014) 'How wrong were we? Dependent interviewing, self-reports and measurement error in occupational mobility in panel surveys', Longitudinal and Life Course Studies 5(3): 299-316.

Richards, L. and Paskov, M. (2016) 'Social class, employment status and inequality in psychological well-being in the UK: cross-sectional and fixed effects analyses over two decades', Social Science \& Medicine 167: 45-53. 
Schneider, S. M. (2016) 'Income inequality and subjective wellbeing: trends, challenges, and research Directions', Journal of Happiness Studies 17(4): 1719-39.

Senik, C. (2009) Income Distribution and Subjective Happiness: A Survey. Paris: OECD. OECD Social, Employment and Migration Working Papers, No. 96.

Stevenson, B. and Wolfers, J. (2008) 'Happiness inequality in the United States', Journal of Legal Studies 37: S33-79.

Streeck, W. (2009) Re-Forming Capitalism, Oxford: Oxford University Press.

Veenhoven, R. (1995) 'The cross-national pattern of happiness: test of predictions implied in three theories of happiness', Social Indicators Research 34: 33-68.

Veenhoven, R. (2005) 'Return of inequality in modern society? Test by dispersion of life-satisfaction across time and Nations', Journal of Happiness Studies 6: 457-87.

Voorpostel, M., Tillmann, R, Lebert, F., Kuhn, U., Lipps, O., Ryser, V.-A., Schmid, F., Antal, E. and Wernli, B. (2014) Swiss Household Panel User Guide 1999-2013, Wave 15, Lausanne: FORS.

Wagner, G., Frick, J. and Schupp, J. (2007) 'The German Socio-Economic Panel study (SOEP) - scope, evolution and Enhancements', Schmollers Jahrbuch 127: 139-69.

Wilkinson, R. and Pickett, K. (2009) 'Income inequality and social dysfunction', Annual Review of Sociology 35: 493-511.

Wulfgramm, M. (2014) 'Life satisfaction effects of unemployment in Europe: the moderating influence of labour market policy', Journal of European Social Policy 24(3): 258-72.

\section{Appendix}
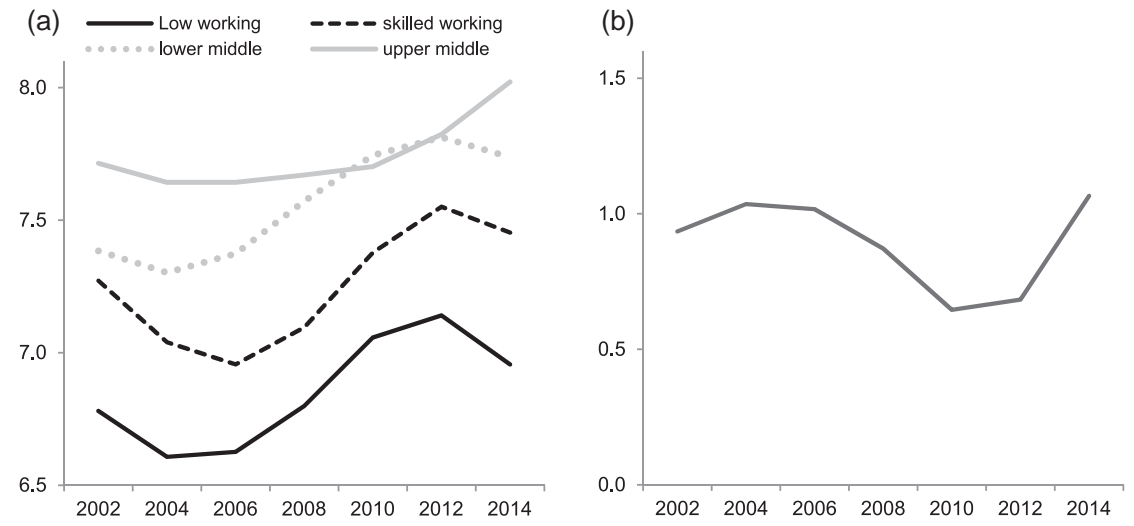

Figure A1. The class gradient in life satisfaction (on a scale from 0 to 10) in Germany (ESS 2002-2014). (a) Life satisfaction by social class in West Germany. (b) Difference in life satisfaction between the upper-middle and low-skilled working class. 

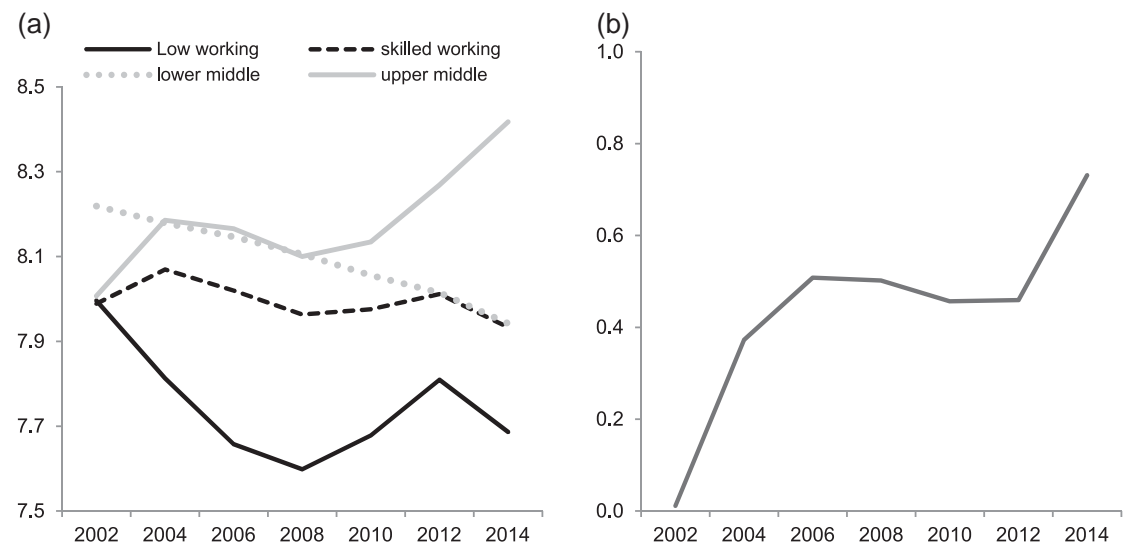

Figure A2. The class gradient in life satisfaction (on a scale from 0 to 10) in Switzerland (ESS 2002-2014). (a) Life satisfaction by social class in Switzerland. (b) Difference in life satisfaction between the upper-middle and low-skilled working class.
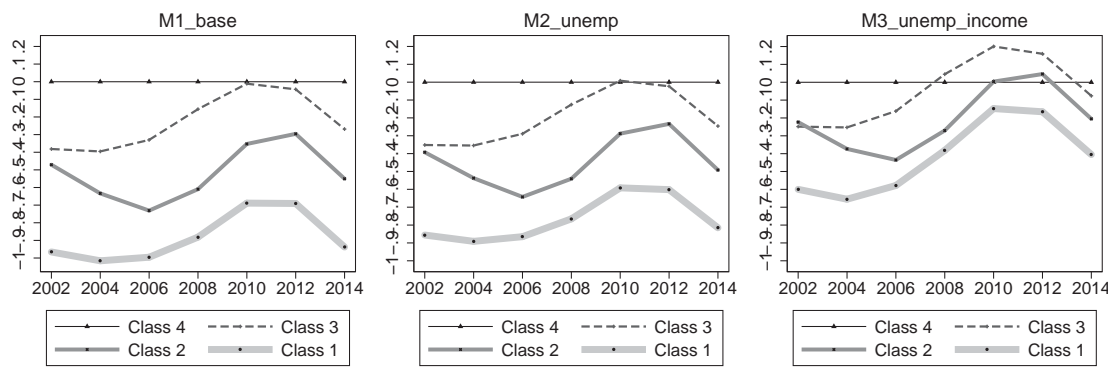

Figure A3. Net class differences in life satisfaction relative to the upper-middle class (on a scale from 0 to 10), Germany 2002-2012. Data: ESS 2002-2014.

Notes: The figures plot the regression coefficients for each class relative to the horizontal line of class 4 (upper-middle class) net of other control variables. Class 1 refers to 'low-skilled working class', class 2 to 'skilled working class' and class 3 to 'lower-middle class'. Model 1 refers to the baseline model with controls for sex, age, partnership, region, nationality. Model 2 additionally controls for individual and regional unemployment, and model 3 for household income and regional income inequality.
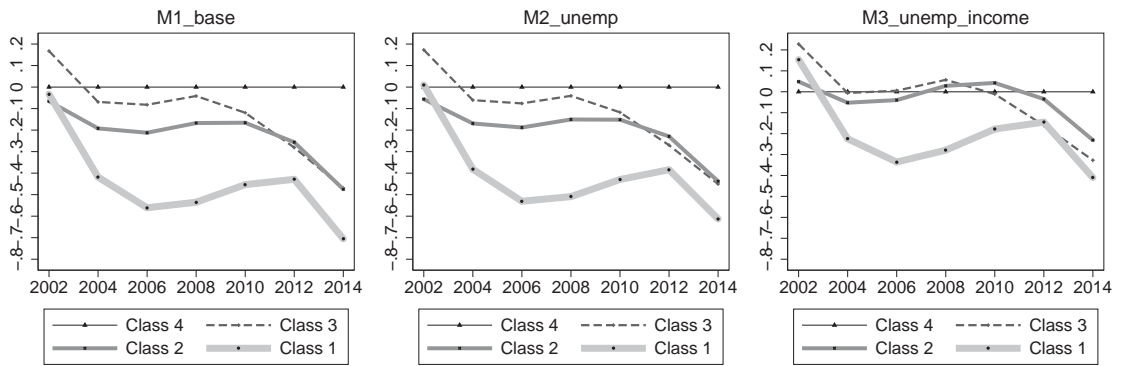

Figure A4. Net class differences in life satisfaction relative to the upper-middle class (on a scale from 0 to 10), Switzerland 2002-2014. Data: ESS 2002-2014. For the legend and model description, see notes in Figure A3. 
Table A1. Descriptive statistics of variables used.

\begin{tabular}{|c|c|c|c|c|c|c|c|c|c|c|c|c|}
\hline & \multicolumn{6}{|c|}{ German SOEP, 1984-2014 } & \multicolumn{6}{|c|}{ ESS-Germany, 2002-2014 } \\
\hline & $N$ & Min & Max & Mean & p50 & sd & $N$ & Min & Max & Mean & p50 & sd \\
\hline Life satisfaction & 250,261 & 0 & 10 & 7 & 7 & 1.8 & 6847 & 0 & 10 & 7.4 & 8 & 1.9 \\
\hline Social class & 250,261 & 1 & 4 & 2.4 & 2 & 0.98 & 6847 & 1 & 4 & 2.5 & 2 & 0.97 \\
\hline Year of observation & 250,261 & 0 & 30 & 16 & 16 & 8.6 & 6847 & 0 & 12 & 6.3 & 6 & 4.1 \\
\hline German nationality & 250,261 & 0 & 1 & 0.9 & 1 & 0.3 & 6847 & 0 & 1 & 0.94 & 1 & 0.25 \\
\hline Male & 250,261 & 0 & 1 & 0.52 & 1 & 0.5 & 6847 & 0 & 1 & 0.51 & 1 & 0.5 \\
\hline Lives with a partner & 250,261 & 0 & 1 & 0.69 & 1 & 0.46 & 6847 & 0 & 1 & 0.74 & 1 & 0.44 \\
\hline Age & 250,261 & 30 & 64 & 46 & 45 & 9.7 & 6847 & 30 & 64 & 47 & 47 & 9.5 \\
\hline $\begin{array}{l}\text { Regional } \\
\text { unemployment } \\
\text { rate }\end{array}$ & 250,261 & 2.3 & 19 & 6.6 & 6.3 & 2.6 & 6847 & 2.8 & 19 & 6.6 & 6.3 & 2.9 \\
\hline Unemployed & 0,261 & 0 & 1 & 0.062 & 0 & 0.24 & 6847 & 0 & 1 & 0.058 & 0 & 0.23 \\
\hline Out of labour force & 250,261 & 0 & 1 & 0.16 & 0 & 0.37 & 6847 & 0 & 1 & 0.24 & 0 & 0.43 \\
\hline $\begin{array}{l}\text { Log equiv. } \\
\text { household } \\
\text { income }\end{array}$ & 250,261 & 1.6 & 14 & 9.7 & 9.7 & 0.53 & 6847 & 0.32 & 12 & 4.2 & 4 & 1.7 \\
\hline \multirow{3}{*}{$\begin{array}{l}\text { P80/20 regional } \\
\text { househ. income }\end{array}$} & 250,261 & 1.7 & 3 & 2.1 & 2.1 & 0.2 & 6847 & 1.1 & 5.3 & 2.2 & 2.1 & 0.69 \\
\hline & \multicolumn{6}{|c|}{ Swiss SHP, 2000-2015 } & \multicolumn{6}{|c|}{ ESS-Switzerland, 2002-2014 } \\
\hline & $N$ & Min & Max & Mean & p50 & sd & $N$ & Min & Max & Mean & p50 & sd \\
\hline Life & 64,623 & 0 & 10 & 7.9 & 8 & 1.4 & 6181 & 0 & 10 & 8 & 8 & 1.5 \\
\hline Social class & 64,623 & 1 & 4 & 2.7 & 3 & 0.99 & 6181 & 1 & 4 & 2.7 & 3 & 0.97 \\
\hline Year of observation & 64,623 & 0 & 15 & 7.5 & 8 & 4.6 & 6181 & 0 & 12 & 5.4 & 6 & 4 \\
\hline Swiss nationality & 64,623 & 0 & 1 & 0.75 & 1 & 0.44 & 6181 & 0 & 1 & 0.84 & 1 & 0.37 \\
\hline Male & 64,623 & 0 & 1 & 0.51 & 1 & 0.5 & 6181 & 0 & 1 & 0.5 & 1 & 0.5 \\
\hline Lives & 64,623 & 0 & 1 & 0.8 & 1 & 0.4 & 6181 & 0 & 1 & 0.78 & 1 & 0.42 \\
\hline Age & 64,623 & 30 & 64 & 46 & 46 & 9.5 & 6181 & 30 & 64 & 46 & 46 & 9.8 \\
\hline $\begin{array}{l}\text { Regional } \\
\text { unemployment } \\
\text { rate }\end{array}$ & 64,623 & 1.5 & 7 & 3.8 & 3.6 & 1.2 & 6181 & 1.7 & 6.4 & 3.8 & 3.7 & 1 \\
\hline Unemployed & $04,0<3$ & 0 & 1 & 0.000 & 0 & 0.079 & 6181 & 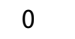 & 1 & & 0 & 0.15 \\
\hline Out of labor force & 64,623 & 0 & 1 & 0.08 & 0 & 0.27 & 6181 & 0 & 1 & 0.22 & 0 & 0.41 \\
\hline $\begin{array}{l}\text { Log equiv. } \\
\text { household } \\
\text { income }\end{array}$ & 64,623 & 2.5 & 15 & 11 & 11 & 0.53 & 6181 & 0.33 & 12 & 4.8 & 4.6 & 2 \\
\hline $\begin{array}{l}\text { P80/20 regional } \\
\text { househ. income }\end{array}$ & 64,623 & 1.8 & 2.5 & 2 & 2 & 0.11 & 6181 & 1.1 & 4 & 1.8 & 2 & 0.62 \\
\hline
\end{tabular}

Note: Control variables are also used for regions (Bundesländer in Germany, greater regions in Switzerland) and the type of sample in the SOEP. 